\title{
Caracterização tecnológica da farinha de grão-de-bico variedade BRS cristalino
}

\section{Technological characterization of BRS cristalino variety chickpea flour}

Thaynnara Cristina Rodrigues Fernandes ${ }^{1}$, Luiz Fernando de Camargos ${ }^{2^{*}}$ (i), Patrícia Aparecida Camilo², Flávio Gonçalves de Jesus ${ }^{3}$, Ana Paula Silva Siqueira ${ }^{4}$

${ }^{1}$ Instituto Federal Goiano, Departamento de Engenharia Agrícola, Urutaí/GO - Brasil

${ }^{2}$ Instituto Federal Goiano, Departamento de Biotecnologia, Urutaí/GO - Brasil

${ }^{3}$ Instituto Federal Goiano, Departamento de Agronomia, Urutaí/GO - Brasil

${ }^{4}$ Instituto Federal Goiano, Departamento de Ciência e Tecnologia de Alimentos, Urutaí/GO - Brasil

*Corresponding Author: Luiz Fernando de Camargos, Instituto Federal Goiano Campus Urutaí, Departamento de Biotecnologia, Rodovia Geraldo Silva Nascimento, Zona Rural, CEP: 75790-000, Urutaí/GO - Brasil, e-mail: luiz.camargos@ifgoiano.edu.br

Cite as: Fernandes, T. C. R., Camargos, L. F., Camilo, P. A., Jesus, F. G., \& Siqueira, A. P. S. (2022).

Technological characterization of BRS cristalino chickpea flour. Brazilian Journal of Food Technology, 25, e2021082. https://doi.org/10.1590/1981-6723.08221

\section{Resumo}

O grão-de-bico é uma oleaginosa de elevada importância comercial e seu cultivo tem sido adaptado para as condições do Cerrado brasileiro. Diante disso, é necessário realizar pesquisas que envolvam essas espécies adaptadas, como o BRS Cristalino, para possibilitar uma maior inserção e expansão neste bioma. Este estudo avaliou características de composição físico-química e tecnológicas do grão cru e seco naturalmente, moído e refinado (farinha). As avalições realizadas foram de umidade, resíduo mineral fixo, lipídeos, proteína, fibras totais, carboidratos e valor energético. A capacidade de absorver água, óleo e leite, e as propriedades gelificantes foram analisadas como propriedades possivelmente interessantes para processos de industrialização. A farinha de grão-de-bico apresentou composição semelhante à da farinha de outras oleaginosas, com teor proteico próximo a 16\%, teor de carboidrato de $61 \%$ e fibra total de $10 \%$. Os índices tecnológicos demonstraram afinidade maior com água e leite, e boa capacidade de gelificação. A partir desses resultados, preparações com farinha de grão-de-bico como ingrediente em produtos alimentícios são motivadas.

Palavras-chave: Cicer arietinum L.; Índices tecnológicos; Farinha; Composição proximal.

\begin{abstract}
The chickpea is an oilseed of high commercial importance and its cultivation was adapted to the conditions of the Brazilian Cerrado. Therefore, studies involving these adapted varieties are necessary, such as BRS Cristalino, in order to enable greater insertion and expansion in this biome. This study evaluated the physicochemical composition and technological characteristics of the raw and naturally dried grains, after being ground and refined. The evaluations carried out were associated with moisture, fixed mineral residue, lipids, protein, total fibers, carbohydrates and energy value. The ability to absorb water, oil and milk and also gelling properties were analyzed as possibly interesting properties for industrialization processes. This composition was similar to the flour of other oilseeds with
\end{abstract}


protein content close to $16 \%$, mineral residue of $2 \%$, carbohydrates of $61 \%$ and total fibers of $10 \%$. The technological indexes showed relevant affinity for water and milk and also good gelation capacity. According to these results, preparations with chickpea flour as an ingredient in food products are motivated.

Keywords:; Cicer arietinum L.; Technological indexes; Flour; Proximal composition.

\section{Highlights}

- Este estudo traz informações da constituição físico-química da farinha de grão-de-bico, obtida de grão adaptado ao Cerrado brasileiro e ainda, apresenta resultados de variáveis tecnológicas que são relevantes para indústria de transformação dos alimentos, em caso de processamento da farinha.

\section{Introdução}

Levando em consideração a relação entre alimentação e qualidade de vida, nos últimos anos, a indústria de alimentos tem demonstrado grande interesse por matérias-primas enriquecidas, principalmente de vitaminas, fibras e minerais, os quais são essenciais para a manutenção do organismo e benéficos à saúde do consumidor (Jaime et al., 2015; Ferreira et al., 2018).

Nessa perspectiva, o grão-de-bico (Cicer arietinum L.) e derivados surgem como matéria-prima de uso potencial na produção de alimentos. O grão, além de ser importante fonte de fibras, carboidratos, vitaminas e minerais, é composto também, de compostos fitoquímicos, como carotenoides, fenólicos e isoflavonas (Wallace et al., 2016; Gupta et al., 2017).

Segundo a Food and Agriculture Organization of the United Nations (2018), o grão-de-bico é cultivado em aproximadamente 45 países, com produção em torno de 13 toneladas. No Brasil, a produção ainda é limitada, o que obriga o País a importar uma parcela significativa para atender à demanda interna (Nascimento et al., 2016) que usa o grão para alimentação humana na forma seca ou industrializada e para forragens. No entanto, essa situação tende a mudar nas próximas décadas com a introdução de variedades adaptadas ao Cerrado brasileiro (Hoskem et al., 2017; Nascimento et al., 2017; Avelar et al., 2018).

Dentre as cultivares comerciais de grão-de-bico, o BRS Cristalino, que faz parte do grupo Kabule, é indicado para cultivo nas regiões de Goiás e Distrito Federal. Essa cultivar tem se destacado por possuir uma boa adaptação à região central do Brasil e também por permitir mecanização da colheita. Com relação aos parâmetros agronômicos, destacam-se: sementes maiores, arredondadas, e maior produtividade em relação ao cultivar BRS Cícero. Na indústria de alimentos, o BRS Cristalino apresenta potencial para ser utilizado tanto na indústria de conservas quanto para consumo do grão seco (Nascimento et al., 2017).

$\mathrm{O}$ estudo e a compreensão das propriedades tecnológicas e do perfil físico-químico do grão-de-bico tornam-se essenciais para estabelecer a relação de consumo do grão com as demandas nutricionais e as características relacionadas ao custo de produção (Santana et al., 2017). A partir das características do grão, é necessário considerar as possibilidades de processamento, como a produção de farinhas, que surge como alternativa de uso, principalmente no setor de panificados, mas também de sobremesas, laticínios e produtos infantis. Estudos apontam o uso eficiente de farinha de grão-de-bico isolada ou associada a farinhas de outras fontes vegetais na composição de produtos de panificação (Arruda et al., 2016). Portanto, antes de usar a farinha, devem-se avaliar o desempenho e o comportamento tecnológico das farinhas, para que seja possível explorar o potencial do produto com o melhor método na produção de alimentos (Silveira et al., 2016).

Diante do exposto, objetivou-se com este trabalho caracterizar a farinha de grão-de-bico BRS Cristalino, visando determinar os parâmetros nutricionais e tecnológicos que podem favorecer seu uso na indústria alimentícia. 


\section{Material e métodos}

\subsection{Local do ensaio}

O BRS Cristalino foi cultivado no ano de 2019, em área experimental, na Fazenda Palmital, Rodovia Geraldo Silva Nascimento Km 2,5, Zona rural, onde está localizado o Instituto Federal Goiano - Campus Urutaí, com área de 307,40 ha, localizada nas coordenadas geográficas $17^{\circ} 29^{\prime} 29^{\prime \prime} \mathrm{S}$ de latitude, $48^{\circ} 12^{\prime} 55^{\prime \prime} \mathrm{O}$ de longitude, em Urutaí-GO (Silva et al., 2015).O Instituto está localizado em região que tem como características geográficas altitude de 712 metros, clima classificado como tropical de altitude, índice médio pluviométrico anual de $2.000 \mathrm{~mm}$ e temperatura média anual de $28{ }^{\circ} \mathrm{C}$ (Silva et al., 2015). Após o cultivo, o grão foi colhido seco, de diferentes plantas, disposto em embalagem de polietileno lacrada e armazenado em laboratório, à temperatura ambiente, até o momento das avaliações.

\subsection{Obtenção da farinha crua de grão-de-bico}

Para a realização dos ensaios, foram utilizados grãos crus íntegros e secos naturalmente, de grão-de-bico BRS Cristalino, que posteriormente foram submetidos à moagem em macromoinho de facas, tipo Willye, da marca Fortinox. Em seguida, refinou-se o produto da moagem em peneira com granulometria de 20 mesh. Como o grão estava seco, não foi realizada secagem após moagem.

\subsection{Composição proximal}

No ensaio de determinação da umidade relativa, foi utilizado o método gravimétrico. Para isso, a amostra foi aquecida a $105^{\circ} \mathrm{C}$, em estufa de convecção, até estabilizar o peso, seis horas. Determinou-se a quantidade de cinzas por meio da calcinação das amostras em mufla a $550^{\circ} \mathrm{C}$ por cinco horas (Association of Official Analytical Chemistry, 2010). Os valores proteicos foram estabelecidos a partir de correlação de nitrogênio total presente na amostra e fator de conversão apropriado para amostras vegetais $(6,25)$, conforme metodologia descrita pela Association of Official Analytical Chemistry (2010), de acordo com método Kjeldahl. A determinação de fibra bruta total deu-se segundo metodologia descrita por Silva \& Queiroz (2009). Para determinar o valor médio do extrato etéreo, utilizou-se como solvente a mistura clorofórmio, metanol e água $(1: 2: 0,8)$ (Bligh \& Dyer, 1959). Para todas as análises, três repetições técnicas foram realizadas.

A quantidade relativa de carboidratos foi determinada por diferença e o valor energético total (VET) foi inferido a partir da conversão de Atwater, que estabelece valores de $4 \mathrm{kcal} / \mathrm{g}$ para proteínas, $4 \mathrm{kcal} / \mathrm{g}$ para carboidratos e $9 \mathrm{kcal} / \mathrm{g}$ para lipídios.

\subsection{Avaliações Tecnológicas}

A caracterização da capacidade absortiva de água (CAA) foi realizada, segundo Okezie \& Bello (1988). Uma amostra de 0,5 grama de farinha foi utilizada para o preparo da mistura, acrescida de $25 \mathrm{~mL}$ de água destilada e, em seguida, agitada e centrifugada por 20 minutos a $5.300 \mathrm{rpm}$. Após isso, o precipitado e o sobrenadante foram separados e utilizados para análises tecnológicas individuais. A partir do líquido sobrenadante, foi determinada a capacidade de solubilização em água (CSA), reduzindo o líquido a $105{ }^{\circ} \mathrm{C}$ até não haver mais variação do peso. Já a CAA foi determinada por diferença entre o líquido adicionado e o recuperado.

Metodologia semelhante foi utilizada para determinar a capacidade da farinha de absorver óleo (CAO) e leite (CAL), para essas determinações utilizou-se como solvente óleo de soja e leite, respectivamente. As capacidades absortivas de água, óleo e leite foram expressas como gramas da emulsão por gramas da amostra (farinha) seca. 
A CSA foi determinada de acordo com a Fórmula (1) expressa abaixo, que estabelece a relação entre o resíduo de evaporação e o peso inicial da farinha.

CSA $=\frac{\text { Resíduo de evaporação }(g)}{\text { Peso da amostra }(g)} \times 100=\%$

A gelificação foi determinada utilizando amostras com concentrações entre 2 e $20 \%$ (peso/volume) em $20 \mathrm{~mL}$ de água e aquecidas a $90{ }^{\circ} \mathrm{C}$ por 30 minutos (Coffmann \& Garciaj, 1977). Posteriormente, as amostras repousaram em temperatura ambiente e foram refrigeradas a $4{ }^{\circ} \mathrm{C}$ por 120 minutos. Por fim, a gelificação foi caracterizada após inversão dos tubos avaliando o gel formado (Figura 1).

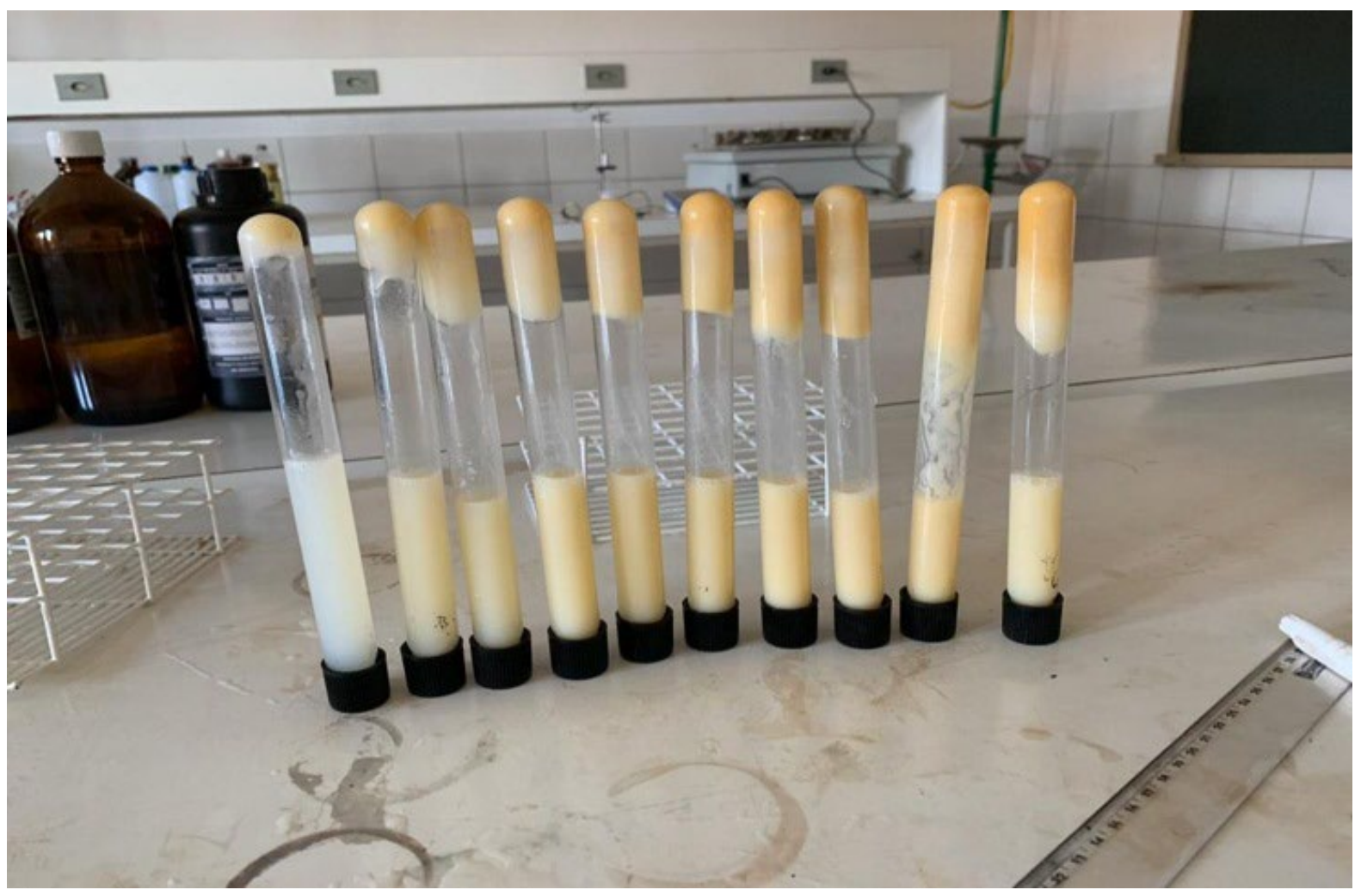

Figura 1. Determinação de potencial de formação de gel por inversão.

\section{Resultados e Discussão}

\subsection{Composição nutricional da farinha crua de grão-de-bico}

Pode-se verificar que o teor de umidade de cerca de $9 \%$ encontrado na farinha de grão-de-bico (Tabela 1) se enquadra nos parâmetros de umidade de farinhas, a qual, de acordo com a ANVISA (Brasil, 1978), deve ter valor máximo de $15 \mathrm{~g} 100 \mathrm{~g}^{-1}$. Logo, a umidade do grão cru, seco, nas condições deste experimento, dispensa tratamentos térmicos prévios, o que reduziria perdas na qualidade nutricional, pela perda de compostos termolábeis.

O parâmetro umidade é utilizado para estabelecer possibilidade de crescimento de microrganismos durante estocagem. Também, para destino comercial dos produtos, correlaciona-se com atividades enzimáticas deletérias derivadas de microrganismos. Assim, quanto menor o teor de água do alimento, maior é sua estabilidade no armazenamento (Santos et al., 2017). Baseado nisso, a farinha obtida apresentaria boa estabilidade no armazenamento, comportamento esperado para farináceos. 
Tabela 1. Composição proximal de farinha de grão de bico BRS Cristalino.

\begin{tabular}{cc}
\hline Variáveis $\left(\mathbf{g} \mathbf{1 0 0} \mathbf{~ g}^{-1}\right)$ & Valores base seca $^{\mathbf{a}}$ \\
\hline Umidade & $8,70 \pm 0,13$ \\
\hline Cinzas & $2,66 \pm 0,01$ \\
\hline Proteínas & $15,74 \pm 0,01$ \\
\hline Lipídeos & $1,90 \pm 0,01$ \\
\hline Fibras totais & $10,18 \pm 1,78$ \\
\hline Carboidratos & $60,82 \pm 1,94$ \\
\hline VET $\left(k c a l 100 \mathrm{~g}^{-1}\right)$ & 322,38 \\
\hline
\end{tabular}

${ }^{a}$ média \pm desvio padrão de três repetições técnicas.

Enquanto a umidade está relacionada, principalmente, ao tempo de secagem do grão em campo, os teores de cinzas, fibras, proteínas e lipídeos da farinha de grão-de-bico (Tabela 1) oscilam não somente entre as variedades, mas também com as condições de cultivo do grão.

O teor de cinzas, ou resíduo mineral fixo, de cerca de 3\% representa o teor de minerais do alimento, os quais têm importância vital para o funcionamento metabólico do corpo humano. Gupta et al. (2017) ressaltam a importância da composição mineral dessa farinha, o que também foi abordado por Kishor et al. (2017), com destaque para ferro, zinco, cálcio e magnésio.

Com relação ao teor proteico de cerca de $16 \%$, a farinha do BRS Cristalino se destaca em relação a outras comercialmente utilizadas, como a de trigo, por exemplo. Dessa forma, a farinha de grão-de-bico pode ser fonte alternativa para produção de alimentos industrializados com destaque para o teor proteico em sua composição e, segundo Kishor et al. (2017), a fração proteica do grão-de-bico tem boa biodisponibilidade.

$\mathrm{O}$ extrato etéreo da farinha em estudo correspondeu a cerca de $2 \%$ e foi menor que o encontrado em outros estudos, relatados anteriormente para o mesmo grão, mas foi semelhante ao relatado para outras leguminosas, como lentilhas $(1,06 \%)$, feijão vermelho $(1,06 \%)$, feijão mungo $(1,15 \%)$ e feijão-guandu $(1,64 \%)$, além de cereais, como trigo (1,70\%) e arroz (cerca de 0,60\%) (United States Department of Agriculture, 2019).

$\mathrm{O}$ alto teor de carboidratos (61\%) encontrado nessa farinha era esperado, pela natureza do material vegetal. Foi encontrado, também, alto teor de fibra bruta no material, cerca de $10 \%$. Com relação à fibra alimentar, Kishor et al. (2017) afirmam que varia de $18 \%$ a $22 \%$ nesse grão, sendo, a maior fração, constituída de fibras insolúveis. As variações nos teores de carboidratos e fibras, além da própria variação entre cultivares, podem ser atribuídas às diferenças no conteúdo de outros constituintes. $O$ valor calórico de $322,38 \mathrm{kcal}^{100 \mathrm{~g}^{-1} \mathrm{da}}$ farinha de BRS Cristalino é muito representando pelo teor de carboidratos do grão.

\subsection{Características tecnológicas de farinha crua de grão-de-bico}

A capacidade absortiva de água da farinha de BRS Cristalino (Tabela 2) se mostrou semelhante à de outras farinhas de oleaginosas, como soja, feijão e linhaça, com valores entre 2\% e 3\% (Santana et al., 2017). Pires et al. (2017) demonstraram que a absorção/solubilidade de água está relacionada ao teor de amido e proteína da farinha, relação importante nos produtos panificados, de forma geral. Ressalta-se que essa relação, além de interferir de forma positiva na textura, também evita ressecamentos da massa.

Tabela 2. Características tecnológicas de farinha de grão de bico BRS Cristalino.

\begin{tabular}{cc}
\hline Variáveis & Valores base seca $^{\text {a }}$ \\
\hline $\mathrm{CAA}^{\mathrm{b}}\left(\mathrm{g} \mathrm{g}^{-1}\right)$ & $2,40 \pm 0,18$ \\
\hline $\mathrm{CAO}^{\mathrm{c}}\left(\mathrm{g} \mathrm{g}^{-1}\right)$ & $1,37 \pm 0,40$ \\
\hline $\mathrm{CAL}^{\mathrm{d}}\left(\mathrm{g} \mathrm{g}^{-1}\right)$ & $2,23 \pm 0,12$ \\
\hline $\mathrm{CSA}^{\mathrm{e}}(\%)$ & $23,68 \pm 5,13$ \\
\hline
\end{tabular}

${ }^{\mathrm{a}}$ média \pm desvio padrão de três repetições técnicas; ${ }^{\mathrm{b}} \mathrm{CAA}$ - Capacidade de Absorção de Água; ${ }^{\mathrm{c}} \mathrm{CAO}$ - Capacidade de Absorção de Óleo;

${ }^{\mathrm{d}} \mathrm{CAL}$ - Capacidade de Absorção de Leite; ${ }^{\mathrm{e}} \mathrm{CSA}$ - Capacidade de Solubilidade em Água. 
A CAO (Tabela 2) da farinha de BRS Cristalino foi similar ao encontrado por Santana et al. (2017) para farinhas de soja e trigo. A absorção do óleo é principalmente conferida pela ligação das proteínas às moléculas do óleo, propriedade que agrada ao paladar e proporciona características adequadas de textura que facilitam sua utilização no preparo de alimentos.

O valor para a CAL (Tabela 2) foi similar ao de água. Essa absorção é importante, pois o leite é uma matéria-prima muito utilizada como ingrediente na indústria de produtos alimentícios processados. Essa matéria-prima está presente na formulação de bolos, sobremesas e molhos, e é uma emulsão O/A. Logo, do ponto de vista tecnológico, isso permite que essa farinha tenha potencial para participar da formulação de um número abrangente de produtos alimentícios.

Ainda de importância tecnológica, comparada com farinhas de outras leguminosas, como soja, feijão, linhaça, além de trigo e aveia (Santana et al., 2017), a farinha de grão-de-bico apresentou solubilidade superior a estas, em água (Tabela 2). A solubilidade em água é interessante, pois dá a possibilidade de uso em preparações que necessitam ser realizadas em baixas temperaturas e também em formulações nas quais os demais componentes da mistura sejam solúveis em água. Esse índice está relacionado também, com outras propriedades tecnológicas da farinha, como formação de gel e espuma, e emulsificação, podendo, portanto, ser considerado um dos mais importantes entre os apresentados.

A capacidade de formação de gel da variedade BRS Cristalino ocorreu em todas as concentrações testadas (2-20\%), de maneira proporcional a esta cocentração (Figura 2). A capacidade de formação de gel é muito importante na indústria alimentícia, pois se relaciona com textura e palatabilidade dos alimentos, principalmente em sobremesas e molhos. Essa capacidade está relacionada com o conteúdo proteico e sua interação com a água. Variedades de grão-de-bico do tipo Kabuli têm uma tendência a formar géis firmes em concentrações baixas, próximo a 10\% (Kaur \& Singh, 2005). Isso pode ser em parte explicado por sua composição proteica, principalmente por proteínas globulares, como Globulina, Glutelina e Albumina (Molina, 2010), que, juntamente com o amido, facilitam a formação de uma matriz de gel firme.

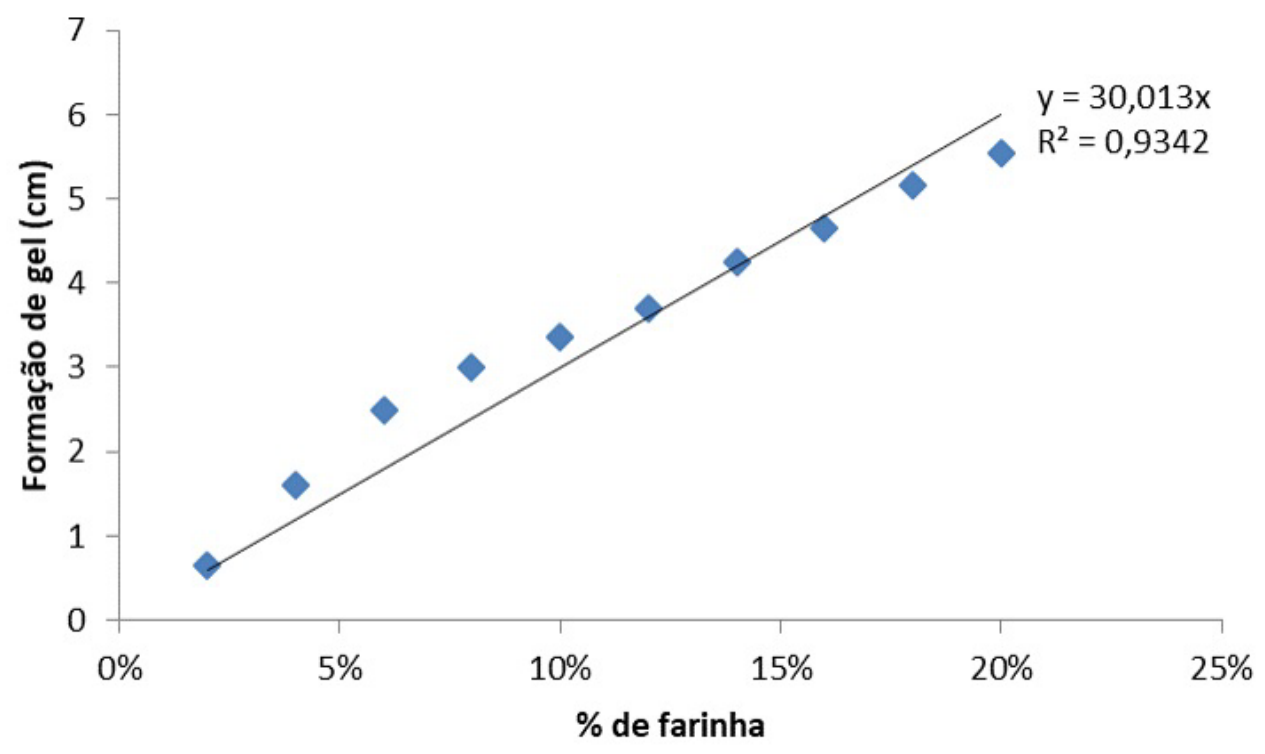

Figura 2. Capacidade de formação de gel de farinha de grão-de-bico BRS Cristalino.

\section{Conclusão}

Os resultados apresentados de parâmetros nutricionais e tecnológicos podem incentivar expansão e instalação de cultivos desse grão, reduzindo a necessidade de importação, hoje realizada no País. Os 
resultados apresentados qualificam o uso tecnológico da farinha na substituição parcial de farinhas tradicionalmente comercializadas ou na composição de formulações enriquecidas.

\section{Agradecimentos}

Ao Instituto Federal Goiano pelo apoio financeiro.

\section{Referências}

Arruda, H. S., Sevilha, A. C., \& Almeida, M. E. F. (2016). Aceitação Sensorial de um pão elaborado com farinhas de cactácea e de grão de bico. Revista Brasileira de Produtos Agroindustriais, 18(3), 255-264. http://dx.doi.org/10.15871/15178595/rbpa.v18n3p255-264

Association of Official Analytical Chemistry - AOAC. (2010). Official methods of analysis of the Association of Official Analytical Chemistry (18th ed., p. 1115). Arlington: Washington.

Avelar, R. I. S., Costa, C. A., Rocha, F. S., Oliveira, N. L. C., \& Nascimento, W. M. (2018). Yeld of chickpeas sown at different times. Revista Caatinga, 31(4), 900-906. http://dx.doi.org/10.1590/1983-21252018v31n412rc

Bligh, E. G., \& Dyer, W. J. (1959). A rapid method of total lipid extraction and purification. Canadian Journal of Biochemistry and Physiology, 37(8), 911-917. PMid:13671378. http://dx.doi.org/10.1139/o59-099

Brasil. Ministério da Saúde. Agência Nacional de Vigilância Sanitária - ANVISA. (1978). Resolução CNNPA n 12 de 1978. Diário Oficial [da] República Federativa do Brasil, Brasília. Recuperado em 10 de abril de 2021, de http://www.anvisa.gov.br

Coffmann, C. W., \& Garciaj, V. V. (1977). Functional properties and amino acid content of a protein isolated from mung bean flour. Journal of Food Technology, 12(5), 473-484. http://dx.doi.org/10.1111/j.1365-2621.1977.tb00132.x

Ferreira, P. M., Roberto, B. S., \& Camisa, J. (2018). Caracterização e aceitabilidade de barras de cereais enriquecidas com colágeno hidrolisado. Revista Virtual de Química, 10(1), 155-171. Recuperado em 10 de abril de 2021, de http://static.sites.sbq.org.br/rvq.sbq.org.br/pdf/v10n1a14.pdf

Food and Agriculture Organization of the United Nations - FAO. (2018). Food and agriculture date. USA: FAOSTAT. Recuperado em 10 de abril de 2021, de https://bit.ly/2gz1a6s

Gupta, R. K., Gupta, K., Sharma, A., Das, M., Ansari, I. A., \& Dwivedi, P. D. (2017). Health risks and benefits of Chickpea (Cicer arietinum) consumption. Journal of Agricultural and Food Chemistry, 65(1), 6-22. PMid:27779388.

http://dx.doi.org/10.1021/acs.jafc.6b02629

Hoskem, B. C. S., Costa, C. A., Nascimento, W. M., Santos, L. D. T., Mendes, R. B., \& Menezes, J. B. C. (2017). Productivity and quality of chickpea seeds in Northern Minas Gerais, Brazil. Agrária, 12(3), 261-268.

http://dx.doi.org/10.5039/agraria.v12i3a5445

Jaime, P. C., Stopa, S. R., Oliveira, T. P., Vieira, M. L., Szwarcwald, C. L., \& Malta, D. C. (2015). Prevalência e distribuição sociodemográfica de marcadores de alimentação saudável, Pesquisa Nacional de Saúde, Brasil 2013. Epidemiologia e Serviços de Saúde : Revista do Sistema Unico de Saúde do Brasil, 24(2), 267-276. http://dx.doi.org/10.5123/S167949742015000200009

Kaur, M., \& Singh, N. (2005). Studies on functional, thermal and pasting properties of flours from different Chickpea (Cicer arietinum L.) cultivars. Food Chemistry, 91(3), 403-411. http://dx.doi.org/10.1016/j.foodchem.2004.06.015

Kishor, K., David, J., Tiwari, S., Singh, A., \& Rai, B. S. (2017). Nutritional Composition of Chickpea (Cicer arietinum) Milk. International Journal of Chemical Studies, 5(4), 1941-1944. Recuperado em 10 de abril de 2021, de https://www.researchgate.net/profile/Kaushal-

Kishor/publication/325809360_Nutritional_Composition_of_Chickpea_Cicer_arietinum_Milk/links/5b25f8d6458515270fd42224/ Nutritional-Composition-of-Chickpea-Cicer-arietinum-Milk.

Molina, J. P. (2010). Fracionamento da proteína e estudo termoanalítico das leguminosas: grão de bico (Cicer arietinum), variedade Cícero e tremoço branco (Lupinus albus L.) (Dissertação de mestrado). Faculdade de Ciências Farmacêuticas, Universidade Estadual Paulista "Julio de Mesquita Filho", Araraquara.

Nascimento, W. M., Silva, P. P., Artiaga, O. P., \& Suinaga, F. (2016). Grão-de-bico. In: W. M. Nascimento (Eds.), Hortaliças leguminosas (pp. 89-118). Brasília: Embrapa.

Nascimento, W. M., Suinaga, F. A., Boiteux, L. S., Pinheiro, J. B., \& Artiaga, O. P. (2017). BRS Cristalino: grão de bico. Nova cultivar de grão-de-bico de dupla aptidão. Brasília: Embrapa Hortaliças. Recuperado em 11 de abril de 2020, de https://bit.ly/2EfS33J

Okezie, B. O., \& Bello, A. B. (1988). Physico-chemical and functional properties of winged bens flour and isolated compared with soy isolated. Journal of Food Science, 53(2), 450-454. http://dx.doi.org/10.1111/j.1365-2621.1988.tb07728.x

Pires, F. C. S., Martins, M. G., Moares, J. F. C., Borges, W. R. F., \& Pena, R. S. (2017). Obtenção, caracterização e utilização de farinha de banana nanicão (Musa sp.) semi-madura na produção de um produto de base láctea. Revista Brasileira de Produtos Agroindustriais, 19(1), 61-72. Recuperado em 11 de abril de 2020, de http://www.deag.ufcg.edu.br/rbpa/rev191/rev1919.pdf

Santana, G. S., Oliveira Filho, J. G., \& Egea, M. B. (2017). Características tecnológicas de farinhas vegetais comerciais. Revista de Agricultura Neotropical, 4(2), 88-95. http://dx.doi.org/10.32404/rean.v4i2.1549 
Santos, E. N., Bezerra, E. A., Silva, L. M. A., \& Cavalcanti, M. T. (2017). Elaboração e caracterização da farinha do fruto da castanhola (Terminalia catappa Linn). Revista Verde de Agroecologia e Desenvolvimento Sustentável, 12(2), 362-365. http://dx.doi.org/10.18378/rvads.v12i2.5337

Silva, A. A. F., Souza, J. A. R., Carvalho, W. B., Mendonça, R. B., \& Moreira, D. A. (2015). Distribuição da umidade do solo num sistema irrigado por gotejamento superficial com diferentes inclinações do terreno. REVENG Engenharia na Agricultura, Viçosa-MG, 23(3), 261-269. http://dx.doi.org/10.13083/1414-3984/reveng.v23n3p261-269

Silva, D. J., \& Queiroz, A. C. (2009). Análise de alimentos: métodos químicos e biológicos (3. ed., 235 p.) Viçosa: UFV. Silveira, M. L. R., Santos, O. S., Penna, N. G., Sautter, C. K., Rosa, C. S., \& Bertagnolli, S. M. M. (2016). Aproveitamento tecnológico das sementes de goiaba (Psidium guajava L.) como farinha na elaboração de biscoitos. Digital Library of Journals, 34(1), 1-20. http://dx.doi.org/10.5380/cep.v34i2.53178

United States Department of Agriculture. - USDA. (2019). FoodData Central. Recuperado em 10 de abril de 2021, de https://fdc.nal.usda.gov

Wallace, T. C., Murray, R., \& Zelman, K. M. (2016). The nutritional value and health benefits of chickpeas and hummus. Nutrients, 8(12), 766. PMid:27916819. http://dx.doi.org/10.3390/nu8120766

Funding: None

Received: Apr. 15, 2021; Accepted: Sept. 02, 2021 Associate Editor: Renato Souza Cruz. 